\title{
The IT convergence framework design in the internet of things environment
}

\author{
Taijong Yoo and Hangbae Chang*
}

\begin{abstract}
In the Internet of things that could intelligent functions such as communications, context awareness, remote control, and provide services to users by assigning advanced communication functions to things, a convergence process between the general manufacturing industry and the IT industry. In detail, the IT convergence is divided into one for the product itself and one for the product manufacturing process. This study designs a model to objectively measure the IT convergence level for the automobile and shipbuilding industries, which are classified as a typical manufacturing industry, and applies it to them so that it would like to acquire availability of the model as well as to provide the present condition of current IT convergence level.
\end{abstract}

Keywords: IT convergence, Convergence measurement, Internet of things environment, Ubiquitous environment, Automobile industry, Shipbuilding industry

\section{Introduction}

The world economy has been changed into the knowledge-based economy due to the development of new IT technologies, and it is expected that the 'fusion technology age' would come closer after the industrial revolution and the computer/communication revolution [1].

In general, a dictionary definition of the convergence is 'that two or more different things are gathered to merge into one without distinction'. The convergence is distinguished from the integration means that unifies functions of sub-systems in accordance with the goal while keeping their inherent nature'. And, the convergence is a phenomenon that creates functions/products/ services previously non-existed by combining different technologies or industries for improving efficiency and performance. Because it is a process expanding and materializing from science to technology, and from technology to industry, it is difficult to understand effects of the 'convergence' in goods and services that are the final products compared to the 'convergence' recognized socially. In addition, it is required to understand the precise meaning of the convergence because the meanings of terms related to the convergence used in the respective countries are slightly different $[2,3]$.

Meanwhile, IT convergence is that facilitates development of technologies and industries in other fields or creates new industries based on IT's own advancement, which concentrates resources and capacity selectively [4,5]. In particular, convergence between technologies such as IT and biotechnology, IT and nanotechnology, etc., is emerged as a method to overcome limits of individual technology and a catalyst to promote industries. In addition, roles of IT are gradually expanded in the key industries such as automobile, shipbuilding, construction, etc., and the importance of IT is increased as means to improve added-values through differentiation.

At this point in time, a study is needed to derive a model, which could measure the IT convergence level by systematically and comprehensively understanding the actual condition of the IT convergence between various industries including IT and manufacturing, and to objectively compare them. Therefore, this study would like to organize diverse concepts of the convergence and to develop a model to measure the IT convergence applicable to the industry.

* Correspondence: hbchang@smu.ac.kr

Division of Business Administration, College of Business, Sangmyung

University, 20, Hongjimun 2-gil, Jongno-gu, Seoul, South Korea

\section{曾}

(c) 2013 Yoo and Chang; licensee Springer. This is an Open Access article distributed under the terms of the Creative Commons Attribution License (http://creativecommons.org/licenses/by/2.0), which permits unrestricted use, distribution, and reproduction in any medium, provided the original work is properly cited. 
Table 1 Definition of IT convergence

\begin{tabular}{llll}
\hline $\begin{array}{l}\text { Convergence } \\
\text { level }\end{array}$ & $\begin{array}{l}\text { First-order (stage 1) } \\
\text { IT convergence }\end{array}$ & $\begin{array}{l}\text { Second-order (stage 2) } \\
\text { IT convergence }\end{array}$ & $\begin{array}{l}\text { Third-order (stage 3) } \\
\text { IT Convergence }\end{array}$ \\
\hline $\begin{array}{l}\text { Convergence } \\
\text { Type }\end{array}$ & $\begin{array}{l}\text { Convergence between IT technologies } \\
\text { and products, or IT technologies and } \\
\text { manufacturing processes }\end{array}$ & $\begin{array}{l}\text { Convergence between the partial social IT } \\
\text { infrastructure and the IT embedded in } \\
\text { products }\end{array}$ & $\begin{array}{l}\text { Convergence between the IT embedded in } \\
\text { heterogeneous industrial products through } \\
\text { the social IT infrastructure }\end{array}$ \\
\hline $\begin{array}{l}\text { Automobile/ } \\
\text { shipbuilding } \\
\text { Industry }\end{array}$ & $\begin{array}{l}\text { Smart (automatic control) vehicle, } \\
\text { digital ship }\end{array}$ & $\begin{array}{l}\text { Intelligent transport systems/shipbuilding e- } \\
\text { navigation }\end{array}$ & $\begin{array}{l}\text { Advanced smart safety vehicles operated in } \\
\text { u-City }\end{array}$ \\
\hline $\begin{array}{l}\text { IT } \\
\text { Requirement }\end{array}$ & $\begin{array}{l}\text { Embedded software, sensor, wire/ } \\
\text { wireless communication devices, data } \\
\text { storage devices }\end{array}$ & $\begin{array}{l}\text { Smart road, wire/wireless communication } \\
\text { devices between vehicles and roads, } \\
\text { compatible communication protocol }\end{array}$ & u-City, u-Healthcare \\
\hline
\end{tabular}

\section{IT convergence concept design \\ Literature review}

Although each country and organization define the convergence, convergence technology, and IT convergence (network convergence), there is no unified opinion. As it is indicated by the terms of interdisciplinary, qualitative changes, common goal, accompanying growth, collapse of boundaries', however, they generally coincide with each other in terms of passing the limits of the existing industries and technologies to describe a new phenomenon.

Convergence is defined as follows. The OECD defines the convergence as "the multiple ways in which nanotechnologies will combine in the future with other developments in new technology reflecting its genuinely interdisciplinary nature." Germany defines the convergence as "a process of qualitative change that connects two or more existing, previously distinct markets." The ITU defines the convergence as "much more than the simple blending together of once-disparate industry segments" [6,7].

And, the convergence technology is defined as follows. The EU defines the convergence technology as "enabling technologies and knowledge systems that enable each other in the pursuit of a common goal." The ITU defines the convergence technology as "a process by which telecommunications, information technology and the media, sectors that originally operated largely independent of one another, are growing together." The United States defines the convergence technology as "the synergistic combination of four major NBIC (nano-bio-info-cogno) provinces of science and technology, each of which is currently progressing at a rapid rate: (a) nanoscience and nanotechnology; (b) biotechnology and biomedicine, including genetic engineering; (c) information technology, including advanced computing and communications; (d) cognitive science, including cognitive neuroscience" [8,9].

Finally, other terms related the convergence are defined as follows. The World Bank defines the IT convergence as "the erosion of boundaries among previously separate services, networks, and business practices in the ICT sector." And, the OECD defines the network convergence as "Convergence refers to the process by which communications networks and services, which were previously considered separate, are being transformed such that: Different network platforms carry a similar range of voice, audiovisual and data transmission services. Different consumer appliances receive a similar range of services. New services are being created."

\section{IT convergence definition}

Organizing the existing common concept of the IT convergence, it could be defined as "a phenomenon that innovates products, services, and processes of other industries, or creates new added values by embedding the

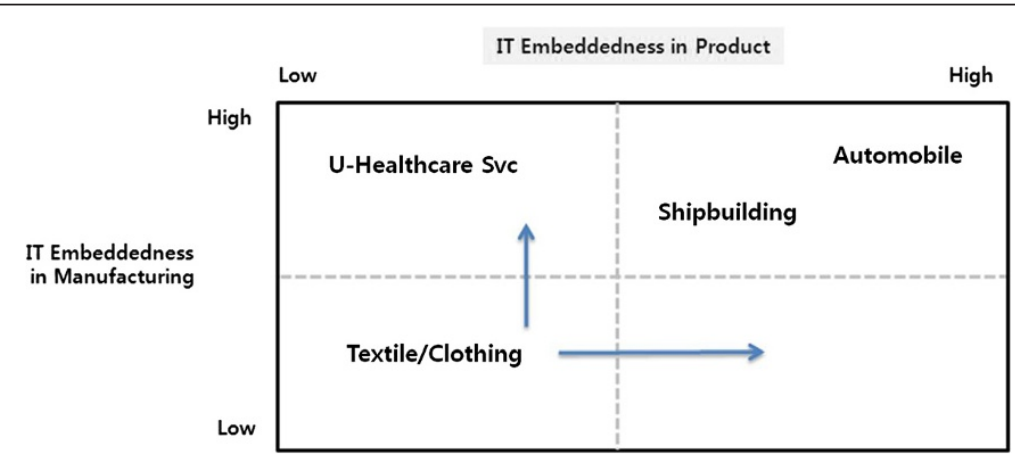

Figure 1 Concept of the IT convergence for each industry. 
Table 2 Target industries for developing IT convergence index

\begin{tabular}{lll}
\hline Strategic industries & IT convergence products & Note \\
\hline Automobile industry & Smart vehicle & Smart (automatic control) vehicle \\
\hline Shipbuilding industry & Smart ship & Digital ship \\
\hline
\end{tabular}

sensing, networking, computing, and actuating technologies of IT as components or modules." This clearly defines the phenomenon converging IT with other and new industries, and describes the effects specifically. However, because it is defined by difficult technical terms to understand for non-professionals, the definition of IT convergence is difficult to understand by the general public or non-professionals. Even though it is defined specifically, the effectively understood concept is not much different from 'innovation' of 'other industries' 'processes, services, and products' 'using IT.' There is a disparate issue continually between the phenomenon of 'IT convergence' and the 'IT convergence industry' analyzed substantially. Like this, the existing definition of 'IT convergence' is a conceptual definition. Arranging the convergence/IT convergence of respective countries, it could be said that the IT convergence is 'advancement of the existing industries' 'converging with IT', and 'creation of new products, services and (added) values' by 'creating new industries.'

Therefore, this article defines the IT convergence in three stages by integrating the systematic and substantial convergence types and the convergence level study of the operational, competent and strategic convergence level [10,11].

The definition of IT convergence is explained in Table 1. Stage 1 is the convergence between IT technologies and products/business processes, and stage 2 means the convergence between the partial social IT infrastructure and the IT embedded in products. And, stage 3 means the IT convergence embedded between heterogeneous industries through the social IT infrastructure.

\section{Design of IT convergence measurement Methodology for designing IT convergence index}

This study separates products and manufacturing processes to develop questions of a survey for the IT convergence in order to measure the extent of convergence between IT and respective industries. Measurements for the first-order could be divided into the extent of converging IT technologies with products representing respective industries and the extent of converging IT technologies with processes as shown in Figure 1. For the processes, automation in most of offices is a common part for each industry.

In this study, target industries for developing the IT convergence index are automobile and shipbuilding as shown in Table 2.

\section{Design of IT convergence index for products}

The methodology of designing a tool to measure the convergence between IT and Products is described as shown in Figure 2. Definition of the convergence between IT and products could be established as the extent of converging IT with functions carried out by core modules or components for each industry. Therefore, core modules or components for each industry are classified for the item category for each industry according to the standard classification system by industry. And, detailed functions performed by core modules or components for each industry are examined to measure the extent of supporting them by IT (the extent of IT convergence).

For key components to measure the convergence level in the automobile industry's product, a total of 25 components are selected from the safety devices, car body control, convenience devices, infotainment, vehicle communication, and power (train) system. For the safety devices, the convergence level is measured for the electronic stability control (ESC), collision avoidance system, pre-crash safety, tire pressure monitoring system, vehicle black box, side obstacle warning system, night vision system, lane department warning system, lane keeping support, front rear monitoring system, distance control between cars, advanced cruise control, intelligence airbag, and vehicle position control. And, for the car body control part, the convergence level is measured for the convenience device control and the lamp control. For the convenience devices, the convergence level is measured for the button starter/smart key/door control system, intelligent park assistant/parking assist system, human-machine interface, driving load control for safe driving, and the vehicle $\mathrm{AV}$ is measured for the
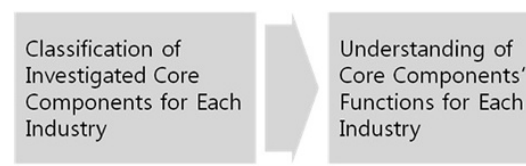

Establishment of the

IT Convergence

Measurement

Standard
Measurement of the

IT Convergence

Extent for Each

Industry

Figure 2 Process of designing a tool to measure the convergence between IT and products. 


\begin{tabular}{|l|l|l|l|l|}
\hline & Understanding of & Establishment of the & Development of \\
\hline Classification of the & Core Processes' & IT Convergence & Measurement Scales \\
Standard & Functions in the & Measurement & Standard for Detailed \\
Manufacturing & Standard & Manufacturing & Manufacturing & Converging IT with \\
Processes for Each & Manufing & Processes for Each & Processes' Functions \\
Industry & Industry & by Industry & Manufacturing \\
\hline
\end{tabular}

Figure 3 Process of designing a tool to measure the convergence between IT and manufacturing processes.

infotainment part. The convergence level of the invehicle network is measured for the vehicle communication, and for the power (train) system, the convergence level is measured for the engine control unit, transmission control unit, hybrid electric vehicle, fuel cell vehicle and, intelligent battery sensor.

For key components to measure the convergence level in the shipbuilding industry's product, a total of 12 components are selected from the propulsion power control, sailing control, accommodation and life safety control, and marine environment control sections. For the propelling power control section, the convergence level is measured for the main propulsion engine and the engine room auxiliary equipment. And, for the sailing control, the convergence level is measured for the cargo stowage, loading and unloading facilities, anchoring/mooring facilities, and navigation systems. For the accommodation and life safety control section, the convergence level is measured for the fire extinguishing and saving equipment and the crew accommodation facilities, and for the marine environment control sections, the convergence level is measured for the harmful substance management and the prevention of marine pollution.

\section{Design of IT convergence index for manufacturing processes}

The methodology of designing a tool to measure the convergence between IT and manufacturing processes is described as shown in Figure 3. Definition of the convergence between IT and manufacturing processes could be established as the extent of converging IT with manufacturing processes for each industry. First, standard

Table 3 Extent of the convergence between IT and the vehicle stability control system device (example)

\begin{tabular}{lll}
\hline Scale point & Division & Description \\
\hline 7 & Full & $\ldots$ \\
\hline 6 & Convergence & \\
\hline 4 & $\begin{array}{l}\text { Considerable } \\
\text { Convergence }\end{array}$ & $\ldots$ \\
\hline 3 & Slight & $\ldots$ \\
\hline 1 & Convergence & \\
\hline
\end{tabular}

processes for each industry are investigated for the item category for each industry according to the standard classification system by industry. And, the standard processes in manufacturing are examined according to the standard for each industry. Then, core manufacturing processes are classified according to the standard for each industry. Finally, it is measured the extent of supporting the detailed processes in the core manufacturing processes for each industry by IT (the extent of IT convergence).

In order to measure the convergence level between IT and manufacturing processes in the automobile industry's product, the convergence level is measured for the whole process of developing new products (product planning, development plan, development implementation, etc.), the whole work to establish a production plan (reflection of the sales forecast and demand plan, planning and managing of available capability, management of work schedules, manpower, etc.), the whole production management work (work order, process control, progress control, etc.) in the business process, and engine mission manufacturing, pressing, car body assembling, painting and final assembling processes in the whole manufacturing process. And, to measure the IT convergence level for the collaboration between companies, the IT convergence level is measured for the production planning and the changed information of orders.

Table 4 Extent of the convergence between IT and a process before developing a new product (example)

Scale point (5-point Ratio of supporting the entire process scales) (product planning, development plan, development implementation, etc.) for developing a new product through an information system

\begin{tabular}{ll}
\hline 5 & $80 \%$ Above \\
\hline 4 & $60-80 \%$ \\
\hline 3 & $40-60 \%$ \\
\hline 2 & $20-40 \%$ \\
\hline 1 & $20 \%$ Below \\
\hline
\end{tabular}

When the full convergence between a product and IT is set as 7 points, and the full convergence between a process and IT is set as 7 points, the reference index is converted into 100 points to make the extent of convergence as an index. And, the convergence index between products and IT and the convergence index between processes and IT are used as a $3 \times 3$ matrix to derive a convergence index describing the IT convergence level by industry. The methodology to derive the IT convergence index by industry and the framework to derive the convergence index is explained as shown in Figure 4. 


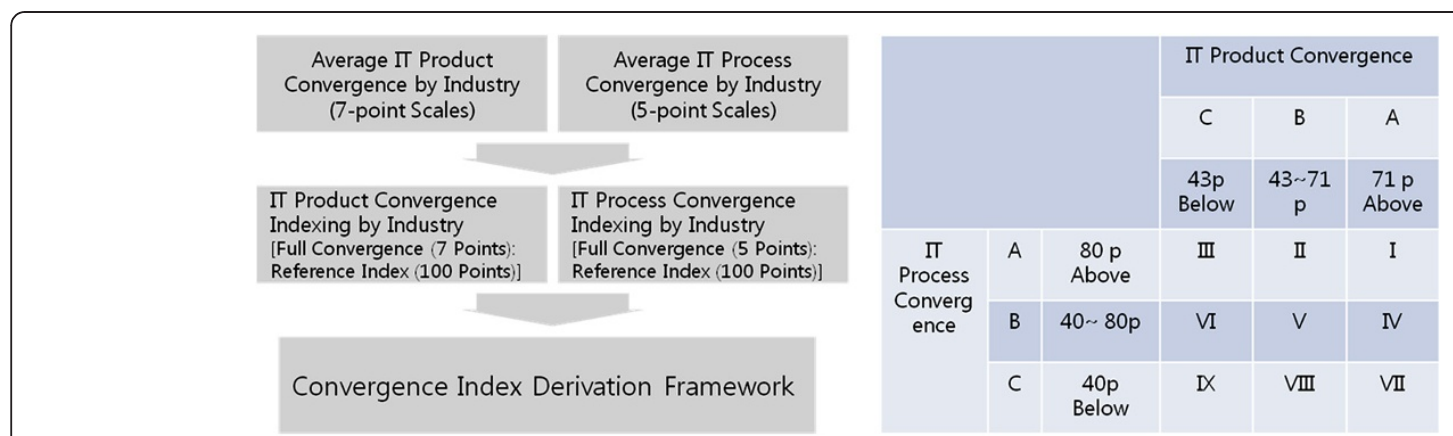

Figure 4 Method to derive the IT convergence index by industry and the framework to derive the convergence index.

In order to measure the convergence level between IT and manufacturing processes in the shipbuilding industry's product, the IT convergence level is measured for the production process of the main company in the business process and the collaboration between companies.

\section{Framework to design IT convergence index}

It is divided into the extent of converging IT technologies with products representing each industry (7-point scales) and the extent of converging IT technologies with processes (5-point scales). Table 3 is an example of measurement scales for the convergence between IT and products, which shows measurements for the extent of the convergence between IT and the vehicle stability control system device. First, the IT convergence level for the product is designed as the 5-point scales from nonconvergence to full-convergence by the corresponding device's intelligence level.

\section{Table 5 Description of IT convergence level}

\begin{tabular}{ll}
\hline 1 & Product IT Convergence A (Good) Level \\
\hline 2 & Process IT Convergence A (Good) Level \\
\hline 3 & Product IT Convergence B (Fair) Level \\
& Process IT Convergence A (Good) Level \\
\hline 4 & Product IT Convergence C (Poor) Level \\
& Process IT Convergence A (Good) Level \\
\hline 5 & Product IT Convergence A (Good) Level \\
\hline 6 & Process IT Convergence B (Fair) Level \\
\hline 7 & Product IT Convergence B (Fair) Level \\
& Process IT Convergence B (Fair) Level \\
\hline 8 & Product IT Convergence C (Poor) Level \\
& Process IT Convergence B (Fair) Level \\
\hline 9 & Product IT Convergence A (Good) Level \\
& Process IT Convergence C (Poor) Level \\
\hline
\end{tabular}

And, Table 4 is an example of the measurement scales for the convergence between IT and processes, which shows measurements for the extent of the convergence between IT and a process before developing a new product. The IT convergence level of the product manufacturing process is designed as the 5-point scales from below 20\% to above $80 \%$ by the extent of utilizing IT technologies on the process.

Passing through the framework as Figure 4, the extent of the IT convergence for each industry is derived depending on the corresponding section of I-IX as follows in Table 5.

\section{Empirical analysis of the model to measure IT convergence index}

Survey design on IT convergence index

The survey for measuring the IT convergence index was conducted for 129 companies in Korea, which the IT convergence level could be measured, targeting persons responsible for the business of the company having products and processes. For the automobile industry, it was targeted at the manufacturers of the corresponding products above 10 billion won of sales or the major

Table 6 IT convergence index weights for the automobile and shipbuilding industries

\begin{tabular}{|c|c|c|c|}
\hline Industry & Division & IT convergence target & Weight \\
\hline \multirow[t]{8}{*}{ Automobile } & Product & Safety device & 0.25 \\
\hline & & Body control & 0.18 \\
\hline & & Convenience device & 0.14 \\
\hline & & Infotainment & 0.11 \\
\hline & & Vehicle communication & 0.21 \\
\hline & & Power transmission device & 0.07 \\
\hline & Process & OEM & 0.67 \\
\hline & & Cooperative company & 0.33 \\
\hline \multirow[t]{6}{*}{ Shipbuilding } & Product & Propulsion power & 0.10 \\
\hline & & Sailing control & 0.30 \\
\hline & & Resident life & 0.40 \\
\hline & & Marine environment management & 0.20 \\
\hline & Process & OEM & 0.33 \\
\hline & & Cooperative company & 0.67 \\
\hline
\end{tabular}


Table 7 Extent of the convergence between IT and the vehicle stability control system device (example)

\begin{tabular}{|c|c|c|}
\hline Scale point & Division & Description \\
\hline 7 & Full & \multirow{2}{*}{$\begin{array}{l}\text { A state that the ESC converged with IT automatically detects every situations related to sudden cornering and } \\
\text { cornering (ex: terrain conditions of driving roads, positions of steering, rotational speed of wheels and centrifugal } \\
\text { force of vehicles etc.) to automatically control the vehicle's optimum position (ex: individual driving force control } \\
\text { for each wheel, engine power control, antiskid, brake assist and hold, active headrest etc.) for accident prevention } \\
\text { and vehicle running stability }\end{array}$} \\
\hline 6 & Convergence & \\
\hline 5 & Considerable & \multirow{2}{*}{$\begin{array}{l}\text { A state that the ESC converged with IT automatically detects partial situations related to sudden cornering and } \\
\text { cornering (ex: part of terrain conditions of driving roads, positions of steering, rotational speed of wheels and } \\
\text { centrifugal force of vehicles etc.) to automatically control the vehicle's position depending on the recognized } \\
\text { situations for accident prevention and vehicle running stability }\end{array}$} \\
\hline 4 & Convergence & \\
\hline 3 & Slight & \multirow{2}{*}{$\begin{array}{l}\text { A state that the ESC converged with IT automatically detects partial situations related to sudden cornering and } \\
\text { cornering, and provides the recognized information (ex: sliding condition levels of road surfaces) to effectively } \\
\text { control the vehicle manually by drivers for accident prevention and vehicle running stability }\end{array}$} \\
\hline 2 & Convergence & \\
\hline 1 & No convergence & A state that drivers control the vehicle's position manually \\
\hline
\end{tabular}

company's subcontractors. And, for the shipbuilding industry, it was targeted at the major shipbuilders focused on the large companies, manufacturers of the corresponding products among the small medium shipbuilders or the major company's subcontractors, and the major company's subcontractors above 30 billion won of sales. And, preparing the questionnaire reflecting characteristics for each industry, it was conducted by letter (e-mail,) telephone, and interview. The questions were weighted through the priority investigation of the survey's questions and the analytic hierarchy process method was utilized to carry out the data coding reflecting the weight as Table 6 and verification. The analytic hierarchy process (AHP) is a structured technique for organizing and analyzing complex decisions. Based on mathematics and psychology.

\section{Survey results on IT convergence index for product and process IT}

Targets for measuring the IT convergence index of the automobile and shipbuilding industries are as follows. For the automobile industry, it measured for safety devices, body control, convenience devices, infotainment, vehicle communications, power transmission devices, OEM systems, and cooperation between companies. For the shipbuilding industry, it is measured for propulsion power engine, sailing control, safety control, marine environment management, OEM systems, and cooperation between companies. For example, the Table 7 shows the Extent of the Convergence between IT and the Vehicle Stability Control System Device.

The IT convergence measurement range of automobile industry was the smart (automatic control) vehicle, and the average IT convergence point of each component was indicated as 3.9 points of the 7-point scales, which is a medium level As a result of survey, the Table 8 shows IT convergence index for the automobile and shipbuilding industries.
Table 8 IT Convergence index for the automobile and shipbuilding industries

\begin{tabular}{|c|c|c|c|c|}
\hline Industry & Division & $\begin{array}{l}\text { IT } \\
\text { convergence } \\
\text { target }\end{array}$ & $\begin{array}{l}\text { IT } \\
\text { convergence } \\
\text { index (by } \\
\text { scales) }\end{array}$ & $\begin{array}{l}\text { IT } \\
\text { convergence } \\
\text { index (based } \\
\text { on 100) }\end{array}$ \\
\hline \multirow[t]{10}{*}{ Automobile } & Product & Safety device & 3.8 & 53.9 \\
\hline & & Body control & 4.3 & 60.7 \\
\hline & & $\begin{array}{l}\text { Convenience } \\
\text { device }\end{array}$ & 3.7 & 52.8 \\
\hline & & Infotainment & 3.8 & 54.4 \\
\hline & & $\begin{array}{l}\text { Vehicle } \\
\text { communication }\end{array}$ & 3.9 & 56.0 \\
\hline & & $\begin{array}{l}\text { Power } \\
\text { transmission } \\
\text { device }\end{array}$ & 3.5 & 50.6 \\
\hline & & Average & 3.9 & 55.9 \\
\hline & Process & OEM & 3.7 & 73.1 \\
\hline & & $\begin{array}{l}\text { Cooperation } \\
\text { between } \\
\text { companies } \\
\end{array}$ & 2.9 & 57.8 \\
\hline & & Average & 3.4 & 68.1 \\
\hline \multirow[t]{8}{*}{ Shipbuilding } & Product & $\begin{array}{l}\text { Propulsion } \\
\text { power }\end{array}$ & 3.2 & 45.9 \\
\hline & & Sailing control & 3.0 & 42.5 \\
\hline & & Resident life & 3.1 & 44.0 \\
\hline & & $\begin{array}{l}\text { Marine } \\
\text { environment } \\
\text { management }\end{array}$ & 2.8 & 40.5 \\
\hline & & Average & 3.0 & 43.0 \\
\hline & Process & OEM & 2.7 & 54.3 \\
\hline & & $\begin{array}{l}\text { Cooperation } \\
\text { between } \\
\text { companies }\end{array}$ & 2.6 & 51.1 \\
\hline & & Average & 2.6 & 52.2 \\
\hline
\end{tabular}




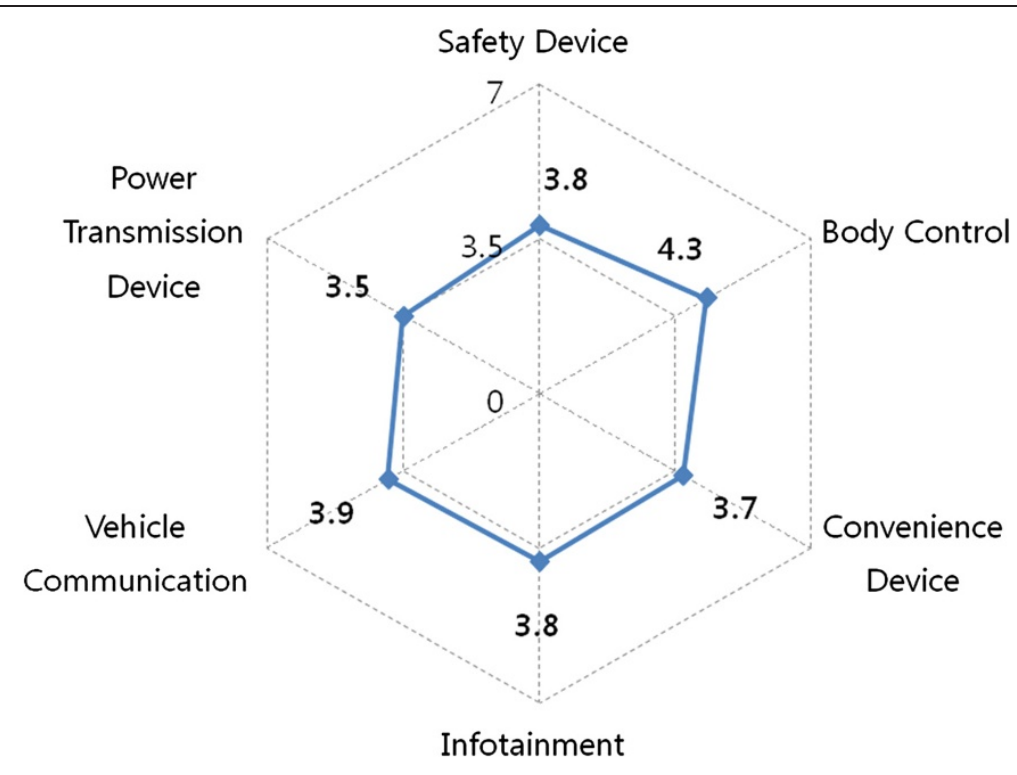

Figure 5 Analysis of the automobile product-IT convergence components.

Figure 5 shows the analysis of the automobile product-IT convergence components. Of the product's components, the body control device was 4.3 points, which showed the highest IT convergence, in addition, the vehicle safety system (4.4 points) of the safety devices and the starting and door operating devices (4.7 points) of the convenience devices also indicated the higher IT convergence. However, the infrared camera device (3.2 points) of the safety devices and the safety load control for safe driving (3.0 points) of the convenience devices, etc., showed lower convergence levels than 3.9 points that was the average convergence point of the entire automobile products. The IT convergence with truck, digital tachograph (functions to store and provide the vehicle driving records for checking safety and compliant driving of trucks, etc.), and speed limiting devices showed 3.3, 3.3, and 3.4 points of the 7-point scales, respectively. Figure 6 shows the analysis of the automobile product- IT convergence levels for each detailed item.

In addition, the process-IT convergence level for the automobile was indicated as average 3.4 points of the 5-point scales. The IT convergence level of the OEM system was 3.7 points, which showed relatively high, and it resulted from the high IT convergence of the entire production management work (work order, process control, and progress control etc., 4.4 points) and the pressing process (3.8 points). The IT convergence level of the cooperation system between companies was 2.9 points, which resulted from the low degree of

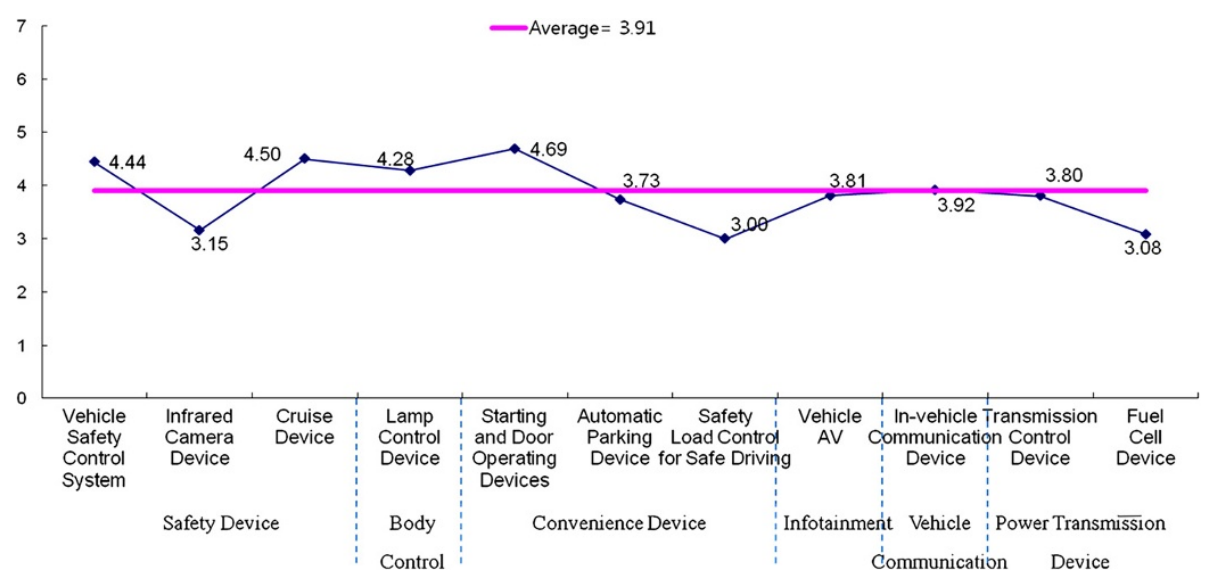

Figure 6 Analysis of the automobile product-IT convergence levels for each detailed item. 


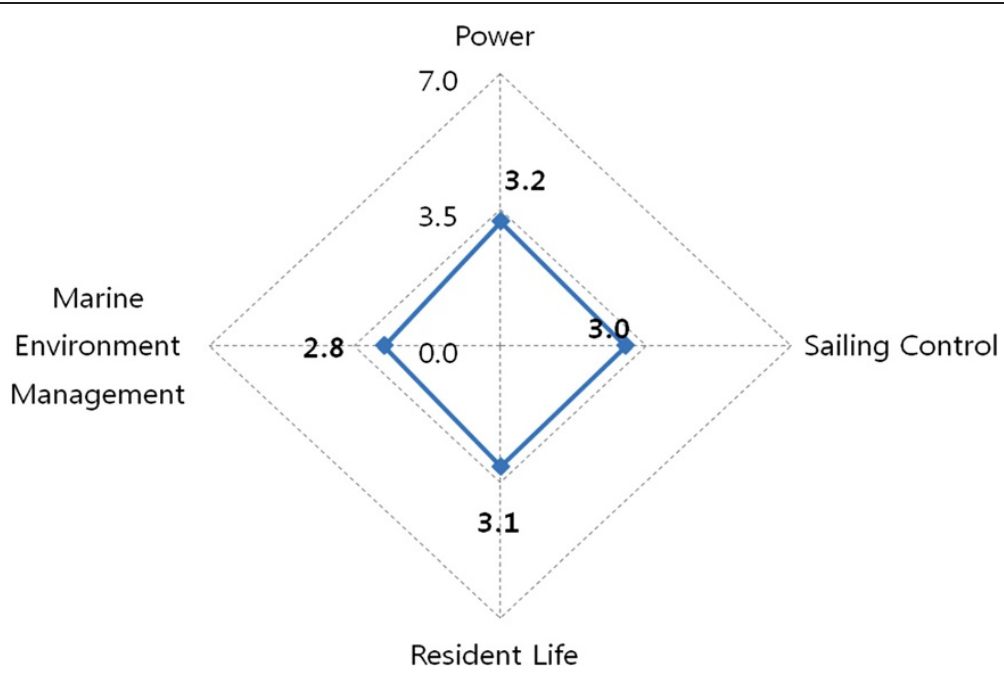

Figure 7 Analysis of the shipbuilding product-IT convergence components.

sharing the OEM production order and order change information with the related companies in real time via an information system.

The IT convergence measurement range of shipbuilding industry was the smart (digital) ship, and the average IT convergence point of each component was indicated as 3.0 points of the 7-point scales, which is a medium level.

Figure 7 shows the analysis of the shipbuilding product-IT convergence components. Of the product's components, the power transmission equipment of the propulsion power engine was 3.3 points, which showed the highest IT convergence, in addition, the disaster warning equipment (3.2 points) of the sailing control and the resident equipment (3.2 points) of the safety control, etc., also showed relatively high IT convergence. However, the anchoring and mooring device (2.5 points) of the sailing control, and the waste disposal equipment (2.8 points) of the marine environment management, etc., showed the lower convergence levels than 3.0 points, the average convergence point of the entire shipbuilding products. Figure 8 shows the analysis of the shipbuilding product- IT convergence levels for each detailed item.

The process-IT convergence level for the shipbuilding industry was indicated as average 2.6 points of the 5 -point scales. The IT convergence level of the OEM system was 2.7 points, the IT convergence of the entire design work (3.5 points) and the entire production management work (3.4 points) were indicated as high, on the other hand, the IT convergence of the assembly process (1.9 points) and the mounting process (2.0 points) showed lower than average. The IT convergence level of the cooperation system between companies was 2.6 points, which showed the real-time sharing of the OEM design change information (2.5 points) and the real-time sharing of the OEM design production schedule change information ( 2.7 points).

\section{Results analysis on IT convergence index at industry level} As shown in Figure 9, even though the automobile industry's IT convergence level is higher than other strategic industries, both of its products and processes are still in the intermediate (V section) level. Of the

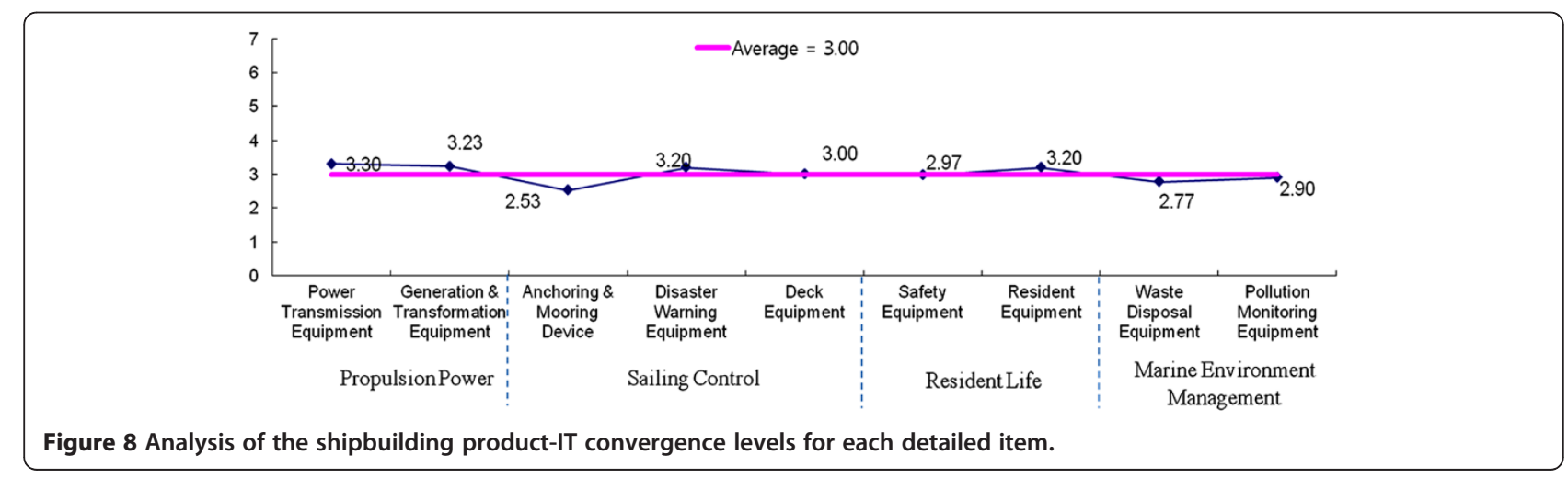


automobile products, the products with the highest IT convergence index are the car body control (61) and the vehicle communication (56), which seems that their complexity is so high that their IT convergence is high because they have a strong interworking function with other components or vehicles rather than the products themselves work autonomously.

In detail, it was represented that the lamp control devices (including the front and rear lamp controls and the in-vehicle lamp control) and the in-vehicle communication devices (MOST, CAN, Flexray, etc.) have the highest IT convergence. The lamp control devices' IT convergence level was represented that the lamps' operation is automatically controlled such as the lamps integrated with IT automatically recognize partial situations (ex: illumination, etc.) related to the lamp actuation and they operate the front lamp for the certain illumination suitable to the recognized situation. The invehicle communication devices' IT convergence level was represented that the in-vehicle communication devices integrated with IT provide the recognized information such as providing the voice manual for connecting with smart-phones for drivers to effectively carry out manual operations by automatically recognizing partial situations related to connections with the invehicle communication.

As shown in Figure 10, it was analyzed that the shipbuilding industry's IT convergence level is still in the intermediate (V section) level for both its products and processes. Of the shipbuilding industry's products, it was found that the products with the highest IT convergence index are the propulsion power engine (46) and the safety control (44), which the IT convergence is being carried out focusing on the ship's main functions, which are related to major devices in the engine room such as the power transmission and the generated voltage, etc., and the crewmen's safety. Since the cargo stowage or control, and the marine pollution prevention equipment, 
etc., are different from major functions of ship building and sailing, it seems that their IT convergence is still low.

\section{Conclusion and future study}

The development and spread of IT has brought about sweeping changes in life styles by innovating paradigms of the entire society. Particularly, in the automobile industry actively utilizing IT, it is developed the convergence products such as the night vision system that automatically delivers actions for drivers to be carried out through images and voice etc. by automatically sensing every condition related to safe driving such as the distance from the forward vehicle, road profile, arrival distance of fallen objects and expected path using a camera being capable of night vision when driving at night. In this way, IT has raised a new issue called the convergence with other technologies or industries, and is lying at the center of changes and innovation. However, since the meaning of the term related to the convergence used in various countries is slightly different, it is necessary to understand the exact meaning of the convergence. In addition, it does not sufficiently reflect the industrial structure change by the recent IT paradigm. And, even though there are detailed industries that the IT convergence is and is not taken place for the certain industries, it is difficult to understand the current situation for them. In addition, IT has raised a new issue called convergence with other technologies or industries, and is located in the center of changes and innovation. However, it was required to understand the precise meaning of the convergence because the meanings of terms related to the convergence used in the respective countries are slightly different. In addition, as demands on the IT convergence have rapidly been increased in every industry, a method was required to produce an IT convergence index, which can systematically and comprehensively understand the real condition of IT convergence between various industries including IT and the manufacturing industry, to compare it objectively.

This article examined and analyzed precedent studies and some nation's definitions of the convergence to redefine the IT convergence. Furthermore, an IT convergence index framework was developed for objectively analyzing the extent of IT convergence. Finally, the empirical analysis was carried out for automobile and shipbuilding industries. Consequently, as the product has higher relation with human life or safety such as the automobile industry's vehicle communication and the shipbuilding industry's safety control, and its working activity is more complicated, it shows that the IT convergence is higher. And, as the product and process plays a bigger role in the industry and has a more fundamental function such as the automobile industry's car body control and the shipbuilding industry's propulsion power engine, it shows that the IT convergence is higher. In other words, it was analyzed that the IT convergence is proportional to the product/process's importance in the industry.

For the future study, it is necessary to carry out an objective verification work additionally for the IT convergence level measurement model developed, and it would extend the measurement model to other industries and conduct a comparison between countries.

\section{Competing interests}

The authors declare that they have no competing interests.

Received: 29 December 2012 Accepted: 31 January 2013 Published: 27 February 2013

\section{References}

1. K Kubiliusa, Y Mishurab, The rate of convergence of Hurst index estimate for the stochastic differential equation. Stochastic Processes and their Applications 122(11), 3718-3739 (2012)

2. S-J Yeon, S-h Hwang, A digital convergence maturity model: the relative importance of factors. Communications in Computer and Information Science 264, 316-323 (2011)

3. Y Kim, J Kang, Y Na, H Chang, Study on development of appraisal business performance indicator. Lecture Notes in Electrical Engineering 164, 417-423 (2012)

4. Z Jiangfeng, K Thomas, K Maria, CM Soukoulis, Negative refractive index response of weakly and strongly coupled optical metamaterials. Physical Review B 80(3), 1-6 (2009)

5. SL Jack, AR Anderson, The effects of embeddedness on the entrepreneurial process. Journal of Business Venturing 17(5), 467-487 (2002)

6. M Shalaby, S El-Kassas, Applying Scrum framework in the IT service support domain. Journal of Convergence 3(1), 21-28 (2012)

7. M Karvonen, T Kassi, Patent citation analysis as a tool for analysing industry convergence, in Proceedings of the Technology Management in the Energy Smart World (PICMET) (, California, USA, 2011), pp. 1-13

8. T Bjerregaard, Industry and academia in convergence: micro-institutional dimensions of R\&D collaboration. Technovation 30(2), 100-108 (2010)

9. W Xing, X Ye, L Kui, Measuring convergence of China's ICT industry: an input-output analysis. Telecommunication Policy 35(4), 301-313 (2011)

10. Johannison et al., The institutional embeddedness of local inter-firm networks: a leverage for business creation. Entrepreneurship and Regional Development 14, 297-315 (2002)

11. C Garcia-Pont, J Ignacio Canales, F Noboa, Subsidiary Strategy, The embeddedness component. Journal of Management Studies 46(2), 182-214 (2009)

doi:10.1186/1687-1499-2013-53

Cite this article as: Yoo and Chang: The IT convergence framework design in the internet of things environment. EURASIP Journal on Wireless Communications and Networking 2013 2013:53.

\section{Submit your manuscript to a SpringerOpen ${ }^{\odot}$ journal and benefit from:}

- Convenient online submission

- Rigorous peer review

- Immediate publication on acceptance

- Open access: articles freely available online

- High visibility within the field

- Retaining the copyright to your article

Submit your next manuscript at springeropen.com 